\title{
Impacto do adoecimento crônico em mulheres com Vírus Linfotrópico T Humano (HTLV)
}

\author{
Impact of chronic illness in women with \\ Human T-Lymphotropic Virus (HTLV)
}

\author{
Ana Clarissa Cerqueira dos Santos ${ }^{1}$ \\ Daniela Carneiro Sampaio ${ }^{2}$ (c) \\ Lavinya Lima Cordeiro Oliveira 3 (1)
}

\author{
Dhynar Alves dos Santos Ribeiro 4 (1) \\ Bruna Rafaella Barreto Sousa 5 (1) \\ Maria da Conceição Costa Rivemales ${ }^{6}$ (1)
}

${ }^{1}$ Autora para correspondência. Universidade Federal do Recôncavo da Bahia (Santo Antônio de Jesus). Bahia, Brasil. santosanjoclarissa@gmail.com 2-6Universidade Federal do Recôncavo da Bahia (Santo Antônio de Jesus). Bahia, Brasil. daniela_sampaio1305@hotmail.com, lavinyalima@outlook.com, dhyna.gama.santos@hotmail.com, brunarafaellas2@hotmail.com, mariarivemales@ufrb.edu.br

RESUMO | OBJETIVO: Analisar de que modo às alterações causadas pelo HTLV impactam no cotidiano das mulheres e as formas de enfretamento a presença do referido vírus. MÉTODO: Pesquisa descritiva qualitativa realizada com utilização de dados secundários extraídos a partir da base de dados do projeto de pesquisa intitulado "Vivência da sexualidade: representações das pessoas soropositivas para o HTLV". A coleta de dados foi feita com 12 mulheres HTLV positivas atendidas no ambulatório de infectologia de um Hospital Universitário em Salvador/BA; e no Centro de Testagem e Aconselhamento (CTA) do município de Santo Antônio de Jesus/BA, utilizando como estratégia metodológica o Discurso do Sujeito Coletivo. RESULTADOS: Os depoimentos e falas de mulheres soropositivas para o HTLV revelam o estigma vivenciado por elas, o afastamento de amigos e familiares após o diagnóstico do HTLV e o impacto negativo para as mulheres. Quanto às formas de enfrentamento para driblar o estigma, as mulheres ocultam detalhes relacionados à infecção pelo HTLV e encobrem totalmente sua condição sorológica, até mesmo para seus familiares. CONCLUSÃO: O HTLV causa impactos no cotidiano das mulheres que convivem com o vírus. Assim, a assistência de saúde prestada deve ser baseada no bem estar físico e biopsicossocial, contribuindo assim, com o enfrentamento do estigma no cotidiano da mulher soropositiva.

\begin{abstract}
OBJECTIVE: To analyze how the changes caused by HTLV impact the daily lives of women and the ways of coping with the presence of the virus. METHOD: Qualitative descriptive research was carried out using secondary data extracted from the research project database entitled "Experience of sexuality: representations of people seropositive for HTLV." Data collection was carried out with 12 HTLV positive women seen at the infectology clinic of a University Hospital in Salvador, Bahia, Brazil, and at the Testing and Counseling Center (CTA) in the city of Santo Antonio de Jesus, Bahia, Brazil, using the Collective Subject Discourse as a methodological strategy. RESULTS: The testimonies and speeches of HTLV seropositive women reveal the stigma experienced by them, the withdrawal of friends and family after the diagnosis of HTLV, and the negative impact of these for women. Concerning coping with circumventing the stigma, women hide details related to HTLV infection or even completely cover up their serological condition, even for their family members. CONCLUSION: Thus, it is clear that HTLV impacts women's daily lives living with the virus. Thus, the health care provided should not be based only on physical well-being but also on their biopsychosocial well-being, thus contributing to coping with the stigma in the daily lives of HIV-positive women.
\end{abstract}

DESCRIPTORS: HTLV virus. Social stigma. Women.

DESCRITORES: Vírus HTLV. Estigma social. Mulheres. 


\section{Introdução}

$\mathrm{O}$ vírus linfotrópico de células T humanas ( HTLV) apresenta-se em quatro tipos HTLV-1, HTLV-2, HTLV3 e HTLV-4. O HTLV-1 exibe maior prevalência no mundo sendo associado a patologias como: leucemia/linfoma de células T do adulto (ALT) e a paraparesia espástica tropical (TSP) (doença neurológica) também conhecida como mielopatia associada ao HTLV-1 (HAM); o HTLV-2 apresenta menor risco de desencadear doenças, porém encontram-se relatos na literatura de casos esporádicos de sua associação com mielopatia, polineuropatias de predomínio sensitivo e quadros de miopatia inflamatória; já os tipos 3 e 4 foram descobertos na África. ${ }^{1}$ A sua transmissão acontece por via vertical, horizontal e parenteral. 2 De 5 a 10\% dos infectados, em determinado momento da vida, desenvolvem alguma doença relacionada ao HTLV. ${ }^{1}$

A infecção por HTLV apresenta-se como uma condição crônica, tendo manifestações clínicas ou não. Atualmente não há um tratamento específico com a finalidade de combater o vírus, e embora a maioria dos portadores permaneça assintomática, a soropositividade por si só representa um grande impacto em suas vidas, pois sempre há a possibilidade de desenvolvimento de alguma doença. ${ }^{1}$

A doença crônica faz com que a pessoa vivencie uma mudança em diversos aspectos de sua vida, tais como, dificuldades econômicas e relacionais no âmbito familiar, incapacidade para o trabalho e dependência de outras pessoas. ${ }^{3}$ Desta forma, o viver dessas pessoas vai ganhando novos contornos, uma nova forma de se relacionar com o mundo ao seu redor, reavaliando conceitos, valores e crenças, revendo posturas, comportamentos e atitudes frente ao novo contexto. Essas mudanças podem ocorrer juntamente com sentimentos e percepções de perdas, de medo e ansiedade, gerando um sofrimento intenso para o paciente. Além disso, o complexo neurológico associado ao HTLV por ter uma patogenia provavelmente imunomediada pode ser tratado como outras doenças imunológicas do sistema nervoso. No caso do HTLV, a pessoa acometida por esse vírus pode se deparar com o comprometimento da condição física como: alterações posturais, de locomoção, de mobilidade, de perda da continência esfincteriana anal e urinária, que contribuem para a degradação da autoimagem e autoestima das pessoas. $3-5$
Reconhecendo o HTLV enquanto um vírus que causa doenças crônicas, podendo afetar a condição física e neurológica, contribuindo para a degradação da autoestima da mulher, buscou-se analisar de que modo às alterações causadas pelo HTLV impactam no cotidiano das mulheres e as formas de enfretamento a presença do referido vírus.

\section{Métodos e materiais}

Trata-se de um estudo descritivo com abordagem qualitativa, realizado com utilização de dados secundários extraídos da base de dados organizada para o projeto de pesquisa intitulado "Vivência da sexualidade: representações das pessoas soropositivas para o HTLV". A coleta de dados do projeto maior realizouse no ambulatório de infectologia de um Hospital Universitário, Centro de Referência para tratamento às pessoas acometidas pelo HTLV, localizado na cidade de Salvador/BA; e no município de Santo Antônio de Jesus/BA, através das pessoas cadastradas no Centro de Testagem e Aconselhamento (CTA), no período entre março e setembro de 2011.

Participaram da pesquisa 12 mulheres soropositivas e sintomáticas para a infecção pelo HTLV atendidas nos serviços citados anteriormente, tendo como critério de inclusão: serem adultas, terem diagnóstico de soropositividade para o HTLV há pelo menos dois anos e aceitarem participar espontaneamente do estudo.*Os critérios de exclusão foram: serem mulheres HTLV positivas assintomáticas e possuírem diagnóstico sorológico há menos de 02 anos.

A técnica de coleta empregada foi à entrevista em profundidade, a qual permite o acesso a dados de difícil obtenção por meio da observação direta. As entrevistas foram gravadas e posteriormente transcritas para melhor análise e preservação da fidedignidade dos dados

O Discurso do Sujeito Coletivo (DSC) foi à estratégia metodológica eleita para análise dos dados, pois consiste na reunião em um só discurso-síntese homogêneo redigido na primeira pessoa do singular o pensamento de uma coletividade, sujeitos distintos. ${ }^{6}$ Para que essa estratégia seja posta em prática são necessárias figuras metodológicas como: Expressõeschave (ECH) e Ideia Central (IC). As expressões-chave$(\mathrm{ECH})$ corresponde a trechos ou transcrições literais 
do discurso, destacados pelo pesquisador, que revelam a essência do conteúdo discursivo. Enquanto a Ideia Central-(IC) descreve da forma mais sucinta e fidedigna possível, o sentido do discurso analisado. Essa ideia não é uma interpretação e sim uma descrição de um depoimento ou de um conjunto de depoimentos.

A consolidação dos DSCs foi ordenada nas etapas de: transcrição e leitura das entrevistas; identificação da ideia central das falas; atribuição de expressões-chave para identificar as ideias centrais; agrupamento das expressões-chave por aproximação dos significados; organização das falas e análise do discurso, conformando os DSCs, a saber "Ocultamento sobre o HTLV"; "Morte social: afastamento de familiares e amigos"; "Impacto psicológico do HTLV"; “O divino e a família no enfrentamento do HTLV".

Este estudo respeita os aspectos que envolvem a pesquisa com seres humanos, mediante a aprovação do projeto pelo Comitê de Ética em Pesquisa do Complexo Hospitalar Professor Edgar Santos sob protocolo $n^{\circ} 116 / 2010$, e solicitação, aos participantes do estudo, da assinatura do Termo de Consentimento Livre e Esclarecido.

\section{Resultados}

A faixa etária predominante das participantes do estudo foi entre 50 e 59 anos (33,3\%). Quanto à escolaridade predominou as que possuem o estudo fundamental $(58,3 \%)$ e $33,3 \%$ relataram ser casadas. No quesito raça/cor $66,6 \%$ declararam-se pardas.

Os discursos seguintes são constituídos por falas das mulheres sobre as alterações causadas pela soropositividade para o HTLV. Essas alterações regem o modo de viver, estão presente nos corpos e nas relações sociais dessas mulheres, portanto determinam o modo de pensar, agir e interagir. Determinam o modo como estão inseridas na sociedade e como é construída a sua realidade social. Os discursos revelam o estigma vivenciado pelas mulheres, o afastamento de amigos e familiares após o diagnóstico do HTLV, o impacto negativo destes para as mulheres, além de relatar as maneiras que as mulheres utilizam para se fortalecerem a fim de encararem a nova situação que é o adoecimento pelo HTLV e suas consequências.

\section{Primeiro Discurso- Ocultamento sobre o HTLV}

Eu evito comentar, não digo para todo mundo que tenho problema, não revelo o diagnóstico para outras pessoas; porque às vezes as pessoas não entendem, é muita crítica: "porque teve mais parceiro, porque se relacionou com pessoas erradas", então prefiro evitar. Não me sinto bem em conversar, fico envergonhada, receosa. Na minha casa, meus filhos sabem que tenho uma enfermidade no sangue, mas eu procuro não comentar, procuro sempre fugir, não entrar em detalhes, minhas irmãs e minha mãe não sabem, elas não iriam entender, talvez a discriminação viesse a partir delas sem entender o porquê. Afinal, tem muito preconceito ainda, já passei e é terrível, alguém fala assim, "ô menina eu fiquei sabendo que essa doença que você tem não tem jeito não é?" Uma nora mesmo

que morava comigo deixou tudo meu separado, roupas, copo, garfo, separou tudo. Se eu for falar o que eu tenho ai que eu vou ser mesmo excluída da sociedade, eu não falo o que tenho, se a pessoa procura, digo que é problema dos nervos, para não entrar em detalhes.

\section{Segundo Discurso - Morte social: afastamento de familiares e amigos}

As amizades... as amizades tudo se afastaram de mim, deixaram de falar comigo, as pessoas quando ficam doentes perdem tudo, perde amizade, fica sem dinheiro, perde tudo na vida. A maioria dos meus filhos não liga pra mim; parece que eu não existo, tenho 10 filhos e me vejo sozinha, moro só, eu e Deus e vou vivendo até quando Deus quiser. Quando eu estava com minha saúde todo mundo ia me ver, ou mesmo quando eles não vinham eu mesma ia, só que agora eu não tenho condições de ir. "Levo 3, 4, 5 meses sem vê-los, uns ainda vêm me ver, outros nem olham para o lado que eu moro."

\section{Terceiro discurso - Impacto psicológico do HTLV}

Minha vida se transformou, entrei em pânico! Quando (a gente) descobre que tem uma doença que não tem cura a pessoa se desespera; eu não gosto nem de lembrar. Eu fiquei nervosa, fiquei assombrada! A primeira sensação que você tem é de se isolar, chorar, chorar até não poder mais. Eu entrei em depressão, porque a primeira coisa que eu pensei foi, a vida pra mim não existe mais. Eu vivia dentro de casa, não queria ir ao médico. Até remédio de depressão eu estou tomando agora, remédio para dormir também. A gente se sente muito inútil, perde a confiança, eu me vi na cadeira de rodas, uma pessoa que fazia tudo e hoje 
depende dos outros para tomar banho! Sabe qual o valor da minha vida que muitos me davam? Zero. Eu também me dava zero. Depois que fiquei na cadeira de rodas já tentei suicídio três vezes, é tanta coisa que parece que eu vou perder o juízo sabe? Tem dias que se eu pudesse não levantava da cama, gosto mais de ficar

só, não conversar, perdi a alegria de viver. Não tenho mais aquela mesma alegria.

\section{Quarto Discurso - O divino e a família no enfrentamento do HTLV}

Plano eu só tenho um, lutar pela vida! Afinal minha única alegria são "meus filhos", pessoas tão maravilhosas, que me encorajam, pessoas especiais, de confiança. Se Deus não tiver no controle a gente não tem força para suportar, seja HTLV ou a doença que for, tudo tem que ter Deus, sem Ele a gente não é nada, não é ninguém. E é nele que eu invisto minha força. Peço que Ele me dê calma, tire de mim o que não agrada, que tire de mim esse estresse me faça uma pessoa mais calma. Se for da vontade de Deus eu vou ficar boa, nada pra Deus é impossível. Mesmo que os médicos digam que não tem cura, a fé está em Jesus que é o médico dos médicos, creio que vou ser curada em nome de Jesus.

\section{Discussão}

No primeiro discurso, observa-se que a descoberta do vírus faz com a mulher soropositiva vivencie o estigma, seja por parte da família ou da sociedade, assim como a mesma relata: "não revelo o diagnóstico para outras pessoas, se eu for falar vou ser excluída da sociedade", dessa forma, esses indivíduos optam por ocultar a condição de soropositividade. Teixeira et al.. define estigma como uma marca física ou social de conotação negativa que leva o portador dessa "marca" a ser marginalizado ou excluído de algumas situações sociais.

A pessoa e, principalmente a mulher portadora do vírus aparece como dotada de comportamento ou de atitudes impróprias ao bem-estar social, porém consideram que a falta de esclarecimento é, ainda hoje, a grande responsável por situações conflituosas pelas quais passam as pessoas que possuem algum tipo de doença sexualmente transmissível. . $^{-}$

Ademais, o discurso demonstra que a revelação do diagnóstico foi feita somente a alguns familiares, e ainda assim, nem todos os dados foram declarados. Esse silêncio é adotado em combate as críticas que emergem ao se revelar o diagnóstico, principalmente por se tratar de uma infecção que também é transmissível pela via sexual.

Desta forma, se consolida a atitude de omissão de detalhes ou ocultamento do diagnóstico concernente à infecção pelo vírus, não somente para a família, mas também para os amigos. Essa estratégia visa de se proteger de críticas ou da forma como a família e sua rede de relacionamentos reagiriam, haja visto se tratar de um vírus de transmissão sexual. $\mathrm{O}$ O silenciamento sobre a condição sorológica é uma tentativa de proteção do olhar e julgamento alheio e ao mesmo tempo lhes confere um status de normalidade em relação às pessoas que os rodeiam. . $^{-}$

As participantes denotam que o preconceito, associado ao HTLV, pode surgir dos próprios conhecidos, por não entenderem a doença. Essa rejeição decorre normalmente, da semelhança semântica do vírus com o HIV e da percepção sobre a doença (incurável e transmitida sexualmente) que traz uma série de conceitos discriminatórios, embutidos socialmente, desenvolvendo pensamentos de que essas pessoas não são dignas de respeito, pois foram irresponsáveis, promíscuas a ponto de serem infectadas. Por conseguinte, as acometidas sentem-se feridas, envergonhadas e culpadas por terem adquirido tal doença.

Percebe-se igualmente o sentimento de tristeza embutido no relato das discursantes pela falta de apoio e compreensão da própria família, o preconceito é evidenciado pela atitude da nora, que morando na mesma casa, separa tudo de sua sogra por medo de contaminação.

O discurso evidencia ainda que as pessoas sintomáticas para o HLTV são olhadas com discriminação, sendo alvo de preconceito pela sua condição de saúde, pois a partir de sinais físicos presentes no indivíduo enfermo a expressão estética corporal não é vista favoravelmente pela sociedade, por essas manifestações fugirem de um modelo de indivíduo socialmente aceito. ${ }^{9}$

Assim na tentativa de afastar a possibilidade de julgamentos negativos frente a sua condição sorológica as pessoas soropositivas para o HTLV sintomáticas justificam que o comprometimento e/ou limitação 
apresentada é em decorrência de outro problema distinto do HTLV. ${ }^{3}$ A presença desse vírus é um evento marcante e foco de novas direções, pois se inicia um novo modo de viver. Essa nova vida é cheia de estigma e atitudes preconceituosas, que trazem sentimentos de impotência, culpa, tristeza, ressentimentos e vergonha.

No segundo discurso, é possível captar que posteriormente a descoberta do HTLV, ocorre o afastamento de pessoas antes consideradas próximas à mulher acometida. Os achados corroboram com Souza e colaboradores ${ }^{10}$ ao afirmarem que o diagnóstico de uma IST para a maioria das mulheres, resulta em sentimentos negativos e receio de abandono por parte da sociedade.

As pessoas acometidas pelo HTLV experimentam e sofrem o estigma, seja por parte dos membros da família, parceiro sexual ou amigos, seja por si mesma (autoestigma), a confirmação pela infecção do HTLV provoca um afastamento social (e autoisolamento) e esse afastamento acontece com as pessoas do convívio familiar, institucional e social, experiência que se reafirma frente a possibilidade de novas exigências decorrentes da dependência física secundárias à infecção e adoecimento pelo HTLV. 11

A partir do discurso infere-se que enquanto as pessoas estão assintomáticas e fisicamente bem, não há reclusão social, visto que o indivíduo consegue atingir as metas previstas socialmente e tanto familiares quantos amigos sentem-se beneficiados. A perda da capacidade laboral e a diminuição da condição financeira também contribuem para o afastamento das pessoas que esperam daqueles com os quais se relacionam que estas estejam bem e possam também usufruir com ela de uma condição satisfatória. Quando essas expectativas não são alcançadas, há um descrédito e afastamento de "amigos" e familiares. Por tudo isso, as pessoas tendem a se afastar de quem tem o HTLV.12-13

Sumariamente as pessoas consideradas sadias têm uma concepção de que o fato de ter HTLV atribui um sentido de ser "diferente" ou "limitado", o que torna o sujeito rotulado, fazendo com que esse seja excluso de convívios sociais, considerados em sua maioria simples, mas essenciais para o bem-estar da pessoa.
Já no terceiro discurso, exprime uma ideia de medo, tristeza, sofrimento e perda da vida; decorrentes do adoecimento e de suas consequências. Ao descobrir que a progressão da infecção está resultando em um adoecer crônico, há que se ter início ao processo de conscientização e aceitação dessa doença; nesse transcurso vários sentimentos estão enovelados, principalmente se a afecção for transmitida sexualmente e cercada de preconceitos, como no caso do HTLV.

A sobrecarga e a extensão da doença causam frustração e interferem na vida do doente, repercutindo por meio do sentimento de inutilidade, desvalorização, depressão e a sensação de ser um fardo. ${ }^{11}$

Por causa das limitações físicas advindas da doença, as mulheres tornam-se dependentes de outras pessoas, trazendo alterações significativas que repercutem na sua autoimagem e em sua vida cotidiana, essas mudanças fazem desabrochar inúmeros sentimentos tais como o choque, a decepção e a baixa autoestima que levam as pessoas acometidas pelo HTLV a comportamentos depressivos. $\frac{3}{}$ No discurso 3, é perceptível a perda da autoestima, da vontade de conversar, a pessoa prefere viver isolada, enfim perde a vontade de viver.

O adoecer é visto como uma ameaça à vida e a intensidade de suas repercussões depende das características da patologia e da própria pessoa. A presença do HTLV causa diferentes reações, principalmente nos aspectos psicossociais, merecendo destaque "ao desânimo, desesperança, descrença, ansiedade, como as principais alterações percebidas". ${ }^{3}$ As perdas podem ganhar grandes proporções, atingir várias esferas que constituem a vida e comprometer a vida pessoal, afetiva, social, espiritual e profissional.

A progressão da HAM/TSP (paraparesia espástica tropical/mielopatia associada ao HTLV-1) faz emergir sentimentos de medo pela incerteza do futuro e de dependência de outras pessoas, sentimento de desvalia, fracasso, frustração, tristeza e desesperança. Além disso, essa doença é geradora de ansiedade, depressão, irritabilidade e agressividade tanto pela possibilidade como pela presença real da perda da capacidade motora. $\frac{14}{}$ 
Dessa forma pode-se inferir que, um fator estimulante do estresse e consequentemente de outros sentimentos nas mulheres acometidas pelo HTLV é a necessidade de fazer-se presente na clínica de tratamento periodicamente, obrigando-as a faltar no trabalho (quando a sintomatologia do vírus permite que a mesma trabalhe) o que nem sempre é tolerado pela chefia; precisam deixar seus filhos com outras pessoas; além das cobranças, muitas vezes de seus parceiros e familiares, quanto à realização dos seus afazeres, socialmente delegados, que elas não executam para se deslocarem ao tratamento. Destarte o próprio deslocamento é estressante, visto que, a grande maioria precisa sair da cidade onde reside. Todos esses fatos culminam num cansaço físico e emocional, fazendo a pessoa sentir-se inútil e sem confiança como relatado no discurso 3 .

O sentimento de inutilidade é igualmente intrínseco à mulher acometida pelo HTLV, constituindo-se uma situação potencialmente desencadeante de diferentes sentimentos, muito deles relacionados ao sofrimento; visto que as limitações acarretadas pela doença dificultam ou impossibilita a realização de tarefas antes considerada de simples execução. ${ }^{4}$ Comprova-se essa assertiva no seguinte fragmento do discurso "a gente se sente muito inútil [...]. Sabe qual o valor da minha vida que muitos me davam? Zero. Eu também me dava zero".

Frequentemente, a inutilidade não se resume unicamente a restrição física, mas inclui também, a limitação ou perda da tomada de decisões concernentes a sua própria vida. ${ }^{14}$ Essa situação pode reforçar o sentimento de terminalidade do processo de viver, como expresso no relatado: "depois que fiquei na cadeira de rodas já tentei suicídio três vezes". Repercussões emocionais do diagnóstico do HTLV podem induzir à depressão e consequentemente às ideias suicidas. $\frac{5}{}$

O diagnóstico de uma DST, para a maioria das muIheres, resulta em aspectos negativos, principalmente tratando-se de uma doença desconhecida como o HTLV. É essencial o despertar de um novo olhar ao doente com HTLV, considerando não somente os aspectos fisiopatológicos da doença, mas também, as questões psicossociais que entrelaçam o viver dessa pessoa.

Por fim, no quarto discurso, percebe-se o quanto a religião e a família, essencialmente os filhos, são identificados como uma forma de fortalecimento para encarar as fragilidades que o HTLV impõe e o novo traçado necessário à vida da mulher acometida pelo vírus. Algumas pessoas buscam a religião e o apoio familiar predominantemente para amenizar o impacto da enfermidade. $\frac{15}{}$

A doença crônica, por si só, coloca a pessoa em uma situação desconfortável ${ }^{3}$, apreende-se, portanto, que quando se trata da descoberta da soropositividade do HTLV há uma desestruturação mais intensa no cotidiano da pessoa - uma doença desconhecida, de prognóstico incerto, e que ao poder ser transmitida sexualmente é rodeada de preconceitos e estigmas quanto ao comportamento moral dessa pessoa. No entanto, as mulheres acometidas são capazes de criar meios de encorajamento para lidar com as adversidades trazidas abruptamente por tal doença.

A abordagem ao paciente com HTLV e excepcionalmente aquele com HAM/TSP, é de extrema relevância o suporte familiar/social, diante da dependência física e emocional que esses pacientes estabelecem no processo do adoecer e durante a manutenção da vida, sendo um fator determinante para o curso da doença. ${ }^{15}$ É importante, sobretudo, reconhecer que muito há por se fazer pelas famílias que enfrentam a condição crônica. $\frac{14}{}$

Como visto no discurso, mesmo sendo uma doença progressiva e incapacitante, a ideia de ter pessoas que se preocupam com seu bem-estar, impelem as acometidas a buscarem formas de retardar ou minimizar esses acontecimentos, tal como comprovado no trecho: "Plano eu só tenho um, lutar pela vida! Afinal minha única alegria são "meus filhos", pessoas tão maravilhosas, que me encorajam, pessoas especiais, de confiança".

Entende-se ainda a partir do discurso, que a experiência da religiosidade igualmente tem um papel revigorante na vida das mulheres, as quais enxergam Deus numa perspectiva de provedor de suas forças, fazendo-as suportar e superar as dificuldades, como se revelou na fala: "Se Deus não tiver no controle a gente não tem força para suportar. E é nele que eu invisto minha força".

A fé tem tido um importante papel na vida das pessoas, fazendo o indivíduo acreditar numa provisão sobrenatural, capaz de intervir favoravelmente em sua situação concreta de vida, no curso da doença e nos seus efeitos na vida quotidiana, através dela acontece o alívio do sofrimento, do desespero que se instaura na vida de quem adoece. $\frac{16}{}$ 
Observa-se ainda, que a relação com o divino é idealizada não somente como forma de enfretamento, mas também como esperança de cura, ainda que a doença seja incurável, como expresso neste segmento: "mesmo que os médicos digam que não tem cura, a fé está em Jesus que é o médico dos médicos, creio que vou ser curada em nome de Jesus"; É possível encontrar na religião um alento frente às afirmações presentes no discurso médico, de que não há cura. ${ }^{16}$

Assim, compreende-se que os meios de enfretamento ao adoecimento pelo HTLV são essenciais, visto que é uma enfermidade incurável e progressiva que pode levar a agravos significativos como a plegia dos membros inferiores, contribuindo para minimização dos efeitos e melhoria da qualidade de vida. Salienta-se que a terapia medicamentosa não é forma exclusiva de tratar uma doença crônica, mas da mesma forma atitudes que busquem o bem-estar da pessoa, como medidas de conforto, carinho e apoio das pessoas importantes.

Sendo assim, é crucial um olhar mais apurado e mais acolhedor às formas que a pessoa descreve como auxílio no enfretamento da doença, entre os quais estão a religiosidade e a família, pois são recursos de ressignificação da vida, acolhimento das angústias, ajudando-as na busca pela autonomia.

O estudo apresenta algumas limitações, visto que não foi possível a inclusão de mulheres de outros serviços que prestam assistência às pessoas que convivem com o HTLV, bem como de outras regiões do país. Ademais, não foi possível trabalharmos com estratégias para intervir no enfrentamento do estigma, na melhora da autoestima e no autocuidado das participantes.

\section{Conclusão}

As mulheres soropositivas para o HTLV vivenciam o estigma por parte de seus familiares, parceiros e da sociedade, o que se associa ao fato de ser uma doença transmitida sexualmente, marcando-as como dotadas de comportamentos e atitudes indevidas socialmente, entretanto, essas ações preconceituosas podem ser geradas pela falta de conhecimento da doença.

Perante essa situação, várias mulheres lançam mão de estratégias para driblar o estigma, ocultando detalhes relacionados à infecção pelo HTLV, ou ainda encobrindo totalmente sua condição sorológica, até mesmo para seus familiares.

As mulheres acometidas pelo HTLV reconhecem a importância do apoio familiar e da religião para o enfrentamento da infecção/adoecimento. Assim, a assistência de saúde prestada à mulher que vive com o HTLV não deve ser baseada somente no bem estar físico, mas, também no bem estar biopsicossocial, contribuindo assim, com o enfrentamento do estigma no cotidiano da mulher soropositiva.

Salienta-se que o respeito ao exercício da autonomia da mulher soropositiva é imprescindível, afinal a referida infecção pode provocar múltiplas perdas, limitações, entretanto, não significa abolir de suas vidas o poder de decisão sobre si mesmos.

Destaca-se finalmente que os resultados deste estudo trarão informações pertinentes à enfermagem, na condição de uma profissão que cuida, e aos profissionais de saúde de um modo geral, sobre o impacto que o HTLV pode acarretar na vida das mulheres acometidas por esse vírus, contribuindo assim para a promoção do cuidado holístico, que preserve a sua autonomia e vivência biopsicossocial.

\section{Contribuições dos autores}

Todos os autores participaram de todas as etapas do estudo, da escrita e revisão do relato.

\section{Conflitos de interesses}

Nenhum conflito financeiro, legal ou político envolvendo terceiros (governo, empresas e fundações privadas, etc.) foi declarado para nenhum aspecto do trabalho submetido (incluindo, mas não se limitando a subvenções e financiamentos, participação em conselho consultivo, desenho de estudo, preparação de manuscrito, análise estatística, etc.).

\section{Referências}

\footnotetext{
1. Proietti ABFC, organizadora. Cadernos Hemominas HTLV: volume XVI. [Internet]. $6^{\text {a }}$ ed. Belo Horizonte: Fundação Hemominas; 2015. Disponível em: http://www.hemominas. mg.gov.br/publicacoes?download=349:cadernos-hemominas-htlv
} 
2. Glória LM, Damasceno SA, Rodrigues LR, Santos MSB, Medeiros R, Dias GAS, et al. Perfil clínico-epidemiológico de pacientes infectados pelo HTLV-1 em Belém/Pará. Cad. Saúde Colet. 2015;23(2):157-62. https://doi.org/10.1590/1414462X201400050087

3. Santos ACC, Soares DJ, Rivemales MCC. (Des)conhecimento, adoecimento e limitações impostas pelo HTLV: experiências de mulheres soropositivas. Revista Cad. Saúde Colet. 2017;25(1):4550. https://doi.org/10.1590/1414-462×201700010186

4. Pereira DMA, Silva MGAC, Oliveira DC. Qualidade de vida de indivíduos com HIV: uma revisão bibliográfica. Rev. Saúde em foco [Internet]. 2015;2(1): 93-112. Disponível em: http:// www4.unifsa.com.br/revista/index.php/saudeemfoco/article/ download/543/848

5. Souza LS, Sampaio DC, Rivemales MCC, Oliveira LLC, Jesus APS, Lima CFM, et al. Diagnostico de enfermagem em pessoas soropositivas pelo vírus linfotrópico T humano. Rev. Baiana Enferm [Internet]. 2020;34:e37991. Disponível em: https:// periodicos.ufba.br/index.php/enfermagem/article/view/37991

6. Figueiredo MZA, Chiari BM, Goulart BNG. Discurso do Sujeito Coletivo: uma breve introdução à ferramenta de pesquisa qualiquantitativa. Distúrb Comum [Internet]. 2013;25(1):129-36. Disponível em: https://revistas.pucsp.br/index.php/dic/article/ view/14931/11139

7. Teixeira MB, Belmonte P, Engstrom EM, Lacerda A. Os invisibilizados da cidade: o estigma da População em Situação de Rua no Rio de Janeiro. Saúde debate. 2019;43(7):92-101. https:// doi.org/10.1590/0103-11042019s707

8. Dias EA, Sampaio DC, Rivemales MCC, Oliveira LLC, Lima CFM, Santana GMS. Dinâmica familiar de mulheres com vírus linfotrópico T humano. Rev. Baiana Enferm [Internet]. 2019;33: e33675. Disponível em: https://periodicos.ufba.br/index.php/ enfermagem/article/view/33675/20759
9. Souza AS, Kantorski LP, Bielemann VLM. A Aids no interior da família - percepção, silêncio e segredo na convivência social. Acta Sci Health Sci. 2004;26(1):1-9. https://doi.org/10.4025/ actascihealthsci.v26i1.1603

10. Souza ATS, Pinheiro DM, Costa GR, Araújo TME, Rocha SS. As influências socioculturais sobre as doenças sexualmente transmissíveis: análise reflexiva. R Interd [Internet]. 2015;8(1):2406. Disponível em: https://revistainterdisciplinar.uninovafapi.edu. br/index.php/revinter/article/viewFile/573/pdf 204

11. Garcia IFS, Hennington EA. HTLV: uma infecção estigmatizante? Cad. Saúde Pública. 2019;35(11):e00005419. https://doi.org/10.1590/0102-311X00005419

12. Orge G, Travassos MJ, Bonfim T. Convivendo com o HTLV-1. Gazeta Médica da Bahia [Internet]. 2009;79(1):68-72. Disponível em: http://gmbahia.ufba.br/index.php/gmbahia/article/ viewFile/1064/1033

13. Paranhos RFB, Paiva MS, Carvalho ESS. Vivência sexual e afetiva de mulheres com incontinência urinária secundária ao HTLV. Acta Paul. Enferm. 2016;29(1):47-52. https://doi. org/10.1590/1982-0194201600007

14. Silva MEA, Gomes IP, Machado NA, Vaz EMC, Reichert APS, Collet N. Implicações da condição crônica da criança para sua família. Cienc Cuid Saúde. 2014;13(4):697-704. https://doi. org/10.4025/cienccuidsaude.v13i4.20816

15. Gascón MRP, Santos RF, Capitão CG, Nogueira MCF, Oliveira ACP. Um corpo que perde o sentido: uma leitura psicanalítica dos pacientes com paraparesia espástica tropical. Rev. SBPH [Internet]. 2013;16(1):33-48. Disponível em: http://pepsic.bvsalud. org/scielo.php?script=sci_arttext\&pid=S1516-08582013000100003

16. Murakami R, Campos CJG. Religião e saúde mental: desafio de integrar a religiosidade ao cuidado com o paciente. Rev. Bras. Enferm. 2012;65(2):361-7. https://doi.org/10.1590/S003471672012000200024 